\title{
CONSTITUCIONALIDADE DA CONCESSÃO DE BENEFÍCIO DE PRESTAÇÃO CONTINUADA A ESTRANGEIROS RESIDENTES NO BRASIL EM SITUAÇÃO DE MISERABILIDADE
}

\author{
Fabia Sabrina Lins Matias ${ }^{29}$ \\ Marcello Borba Martins Araquan Borges ${ }^{30}$
}

\begin{abstract}
RESUMO
O presente artigo trata do direito ao Benefício de Prestação Continuada a estrangeiros residentes no Brasil e que se adequam aos requisitos de deficiência, idade e não possuem meios de manter o próprio sustento, bem como, o ter mantido por sua família. Para tanto, essa pesquisa se construirá através de conceitos jurídicos e sociais, trazidos por doutrinadores do direito, dentre eles Walber de Moura Agra (2018), Fábio Zambitte Ibrahim (2015) e Alexandre Freitas Câmara (2017), com o intuito de garantir a aplicação de alguns princípios constitucionais tais como a dignidade da pessoa humana e a igualdade. Além disso, será feita uma análise do benefício e seus critérios para concessão, seu amparo legal e jurisprudencial. Como objetivos específicos tem o intuito de descrever acerca da assistência social no Brasil; averiguar a possibilidade de concessão de BPC para estrangeiros residentes no país; e, apresentar alguns casos após o Recurso Extraordinário 587.970 do Supremo Tribunal Federal. A metodologia utilizada foi o método dialético, através da abordagem qualitativa, com caráter bibliográfico-descritivo. Com o deslinde da pesquisa se chega à conclusão quanto a constitucionalidade da concessão de amparo social a estrangeiros que residem no país.
\end{abstract}

Palavras-chave: Assistência Social. Benefício de Prestação Continuada. Estrangeiros. Repercussão geral. Possibilidade.

\section{INTRODUÇÃO}

A Assistência Social, ramificação da Seguridade Social, caracteriza-se como uma garantia do Estado aos necessitados, que visa à plena aplicação do fundamento constitucional da dignidade

29 Graduada em Direito pelo Centro Universitário do Vale do Ipojuca-Unifavip Devry. Email: fabiaslmatias@hotmail.com

${ }^{30}$ Mestre em Direito pela Universidade Federal de Pernambuco (2017). Atualmente é professor universitário do Centro Univeristário Vale do Ipojuca-Unifavip Devry. Email: mb_borba@hotmail.com 
da pessoa humana. Estando no rol dos direitos sociais, vem garantir assistência aos desamparados no valor de um salário mínimo por mês, sem precisar de prévia contribuição para tanto. Encontra seu fundamento constitucional no art. 203, V, da Constituição da República Federativa do Brasil de 1988 (CRFB/88).

Neste contexto, há grande divergência quanto a possibilidade de concessão desse benefício aos estrangeiros residentes no Brasil e que se enquadram nos critérios legais de deficiência/idade e miserabilidade. Assim, o Instituto Nacional do Seguro Social (INSS) vem indeferindo os pedidos com base em critérios do art. $1^{\circ}$ da lei $n^{\circ} 8.742 / 93$. Tal instituto vem dizer que este seria apenas um direito do cidadão, brasileiro nato ou naturalizado, contradizendo com isto muitos princípios presentes no texto maior, sendo um deles a garantia de igualdade entre brasileiros e estrangeiros presente no caput do art. $5^{\circ}$, da $\mathrm{CRFB} / 88$.

O Brasil sempre foi aberto e amistoso quanto a chegada de estrangeiros e não faria sentido uma norma infralegal ir de encontro ao texto constitucional e excluir os estrangeiros da assistência social; fragilizando indivíduos na fase em que mais necessitam de um amparo em sua vida, deficiência e velhice, apenas com fundamento de nacionalidade, ferindo de morte a dignidade da pessoa humana tão buscada no pós-ditadura.

No direito assistencial, o bem tutelado é a subsistência do indivíduo, razão pela qual os benefícios têm caráter alimentar. $\mathrm{O}$ entendimento dos tribunais superiores já caminha por uma perspectiva de possibilidade de amparo a esses sujeitos, sendo inclusive reconhecida a possibilidade através de decisão proferida em sede de repercussão geral pelo Supremo Tribunal Federal (STF).

Neste sentido, levanta-se o seguinte questionamento: é constitucional a concessão de Benefício de Prestação Continuada (BPC) a estrangeiros residentes no Brasil em situação de miserabilidade?

O trabalho tem como objetivo geral analisar a constitucionalidade da concessão de Benefício de Prestação Continuada a estrangeiros residentes no Brasil em situação de miserabilidade. Através dos seguintes objetivos específicos: descrever acerca da assistência social no Brasil; discutir sobre a concessão de Benefício de Prestação Continuada para estrangeiros residentes no país; e, apresentar casos após o Recurso Extraordinário (RE) 587.970 do STF.

Este trabalho se dará mediante a abordagem qualitativa, pois estuda-se através da dinamicidade que tem a realidade e se pauta nas evoluções da sociedade. Deste modo, irá trazer a 
análise e interpretação de conceitos trazidos de diversos ramos do direito e de grandes juristas para exame do tema.

O método desta pesquisa é o dialético. A concepção moderna de método dialético se pauta no conceito de Hegel (apud GIL, 2008, p. 13), no qual dizia que: "a lógica e a história da humanidade seguem uma trajetória dialética, nas quais as contradições se transcendem, mas dão origem a novas contradições que passam a requerer solução”. Assim sendo, este estudo se enquadra na concepção dialética porque irá abordar a aplicação e a compreensão do direito como um sistema normativo não apenas positivista, mas sim com a perspectiva de aplicabilidade ao caso concreto em caso de conflito de normas.

A pesquisa descritiva, utilizada no presente estudo, é aquela que analisa, observa, registra e correlaciona os dados sem manipulá-los. Busca-se fazer uma análise minuciosa do objeto de estudo e o aprofundamento, já que se pressupõe um conhecimento do pesquisador sobre o assunto. Segundo Gil (2008, p. 28): “As pesquisas descritivas são, juntamente com as exploratórias, as que habitualmente realizam os pesquisadores sociais preocupados com a atuação prática".

Foram utilizados documentos como dados, principalmente os jurisprudenciais. Marconi e Lakatos (2003, p. 174) discorrem da seguinte maneira a característica dessa forma de coleta de dados: "A característica da pesquisa documental é que a fonte de coleta de dados está restrita a documentos, escritos ou não, constituindo o que se denomina de fontes primárias”. Essa forma possibilitará a colheita das informações necessárias para todo o discorrer do trabalho além de que permitirá recorrer-se a várias perspectivas da mesma situação, na qual se obterá entendimentos de diversas naturezas.

A técnica a ser utilizada foi a análise de conteúdo. Esse tipo de análise busca a classificação e categorização dos dados coletados e tem o objetivo de ajudar o entendimento dos conteúdos de uma forma sistematiza. Foram utilizados três sistemas de categorias: a) Assistencial social: 1) conceito; b) Possibilidade de concessão do BPC a estrangeiros: 1) sob a ótica legal e 2) interpretação judicial; c) Panorama atual do tema: 1) aplicação prática baseada na jurisprudência.

A importância social do presente tema se dá porque é cada vez maior o número de pessoas que procuram o Poder Judiciário como uma luz ante as decisões arbitrárias do INSS, o que acarreta cada vez mais demandas ajuizadas perante os Juizados Especiais Federais. O grupo que invoca esse auxílio judicial é formado por uma massa hipossuficiente, que em linhas gerais depende do benefício para a sobrevivência. Por isso, o trabalho visa alcançar os integrantes envolvidos nesse 
processo (juízes, advogados, defensores públicos, estudioso do direito etc.) de forma a construirse uma conscientização da importância de debate do tema e de que a aplicação da lei em sentido estrito pode causar danos irreparáveis aqueles que mais dependem dela.

O trabalho também contribuirá academicamente na propagação do estudo do tema que raramente é debatido na academia, mas que ganha mais força diante do fluxo imigratório e da globalização. Caminha por um viés inovador, visto que, poucos trabalhos abordam o tema tratando do cenário criado após a decisão de repercussão geral do STF.

\section{FUNDAMENTAÇÃO TEÓRICA}

\subsection{Assistência Social no Brasil}

Dentre muitas de suas funções, o Estado possui o dever de proteger seus indivíduos no caso de eventos que sejam capazes de impossibilitar a própria subsistência como: desemprego, velhice, morte, prisão, doença, invalidez ou maternidade. Neste contexto, surge a Seguridade Social que consiste em um "conjunto de ações do Estado, no sentido de atender às necessidades básicas de seu povo nas áreas de Previdência Social, Assistência Social e Saúde” (IBRAHIM, 2015, p. 4).

Dentro da Seguridade Social, a assistência social sobreveio com o intento de ajudar o ser humano nos momentos mais difíceis e que mais precisa de ajuda. É um dos instrumentos que objetiva garantir alguns dos fundamentos da República Federativa do Brasil: construir uma sociedade livre, justa e solidária, erradicar a pobreza e a marginalização, reduzir as desigualdades sociais e promover o bem de todos sem quaisquer distinções.

Os direitos sociais estão fundamentados no Capítulo II da Constituição Federal, e o art. $6^{\circ}$ estabelece que: "São direitos sociais a educação, a saúde, o trabalho, a moradia, o lazer, a segurança, a previdência social, a proteção à maternidade e à infância, a assistência aos desamparados, na forma desta Constituição".

Segundo Canotilho (1993, p. 502) os direitos sociais invocariam em três sentidos: em primeiro lugar estes direitos seriam de todos; em segundo lugar haveria uma intervenção prioritária em face daqueles que não estão em páreo de condições sociais, econômicas ou de saúde com os 
demais e por conta disso não poderiam exercer plenamente estas garantias; e, em terceiro lugar a tendência democrática destes direitos que visa uma isonomia entre os cidadãos.

Uma das maiores consequências da globalização é a informatização do trabalho, ocasião que fez diminuir em larga escala o número de trabalhadores nas grandes empresas. Diante desse cenário, é grande a quantidade de trabalhadores que foram obrigados a trabalhar na informalidade (sem anotação na Carteira de Trabalho e Previdência Social - CTPS) e de pessoas aptas a se filiarem como contribuintes individuais que não o fazem, o que diminui a parcela de contribuição na previdência social e faz com que muitos fiquem desamparados em eventos como velhice e incapacidade. Ou seja, o trabalho não possui mais o condão de integrar o indivíduo à sociedade e os programas de assistência social possibilitariam este amparo em detrimento da ausência de proteção social através do trabalho (MOTA, 2006).

Sposati (2007) atenta no sentido histórico de que o Brasil, desde sua criação, sempre possuiu mais trabalhadores informais do que formais, relembra o período de abolição da escravidão, em que os ex-escravos se viam obrigados a trabalhar sem qualquer garantia de direitos para manter sua sobrevivência. A autora afirma que:

Nunca fomos uma sociedade de pleno emprego. Lembremos as barreiras criadas aos negros para sobreviver e trabalhar no pós-libertação da escravidão. No pensamento idealizado liberal permanecia a ideal moral pela qual atribuir benefícios ao trabalhador formal era um modo de disciplinar e incentivar a trabalhar o trabalhador informal, tido por vadio (SPOSATI, 2007, p. 12-13).

Assim, a assistência social serve para integrar o indivíduo a sociedade e para diminuir a exclusão social, que é passada geralmente para as futuras gerações do grupo familiar caso não haja a intervenção estatal. Os seus recursos são da seguridade social e exigir contribuição desses indivíduos só aumentaria a desigualdade e a inacessibilidade dessa população marginalizada (AGRA, 2018).

O texto maior de 1988 elencou o tema da assistência social em seus arts. 203 e 204. O art. $203^{31}$ da Constituição Federal de 1988 diz que será prestada a quem dela necessitar, ou seja, aqueles indivíduos que não possuem condições financeiras de manter o próprio sustento ou de tê-lo provido por sua família, também não necessitará de contribuição para tanto. Já o inciso V traz expressamente a garantia a percepção do BPC: "a garantia de um salário mínimo de benefício

\footnotetext{
${ }^{31}$ Art. 203. A assistência social será prestada a quem dela necessitar, independentemente de contribuição à seguridade social, e tem por objetivos:
} 
mensal à pessoa portadora de deficiência e ao idoso que comprovem não possuir meios de prover à própria manutenção ou de tê-la provida por sua família, conforme dispuser a lei”.

Além disso, o benefício também possui respaldo infralegal na Lei n 8.742 de 1993 conhecida popularmente como LOAS (Lei Orgânica de Assistência Social), que regula a forma de organização da assistência social.

O Benefício de Prestação Continuada, também conhecido como Benefício de Amparo Assistencial, é uma ajuda no valor de um salário mínimo concedido a idosos ou pessoas com deficiência que preencherem os requisitos trazidos pela norma.

Para isso, é necessário o preenchimento de alguns requisitos, quais sejam: a miserabilidade, comprovada por aquele que tenha como renda per capita do grupo familiar o valor inferior ao $1 / 4$ (um quarto) do salário mínimo; idade de 65 (sessenta e cinco) anos para os idosos ou prova da deficiência que impossibilite o exercício de atividade laborativa pelo período mínimo de dois anos.

Com relação ao critério de miserabilidade, o STF declarou incidentalmente a inconstitucionalidade do $\S 3^{\circ}$ do art. 20 da LOAS, por entender que o critério da renda per capita de 1/4 (um quarto) do salário mínimo estaria defasado para análise da miserabilidade e que o Juiz deveria analisar outros aspectos para julgar este ponto (STF RE 567985 e RE 580963, 2013). Por não ter pronúncia de nulidade, o referido parágrafo continua no ordenamento jurídico, contundo, não exclui a análise global da situação financeira do beneficiário (STF ARE 834476, 2015).

Também há a súmula 79 da Turma Nacional de Uniformização (TNU) dos Juizados Federais Especiais Federais, julgada em 15/04/2015, que diz: "Nas ações em que se postula benefício assistencial, é necessária a comprovação das condições socioeconômicas do autor por laudo de assistente social, por auto de constatação lavrado por oficial de justiça ou, sendo inviabilizados os referidos meios, por prova testemunhal." Ou seja, serão utilizados outros métodos de avaliação pelo juiz.

\subsection{Concessão de Benefício de Prestação Continuada aos Estrangeiros Residentes no Brasil}

A lei $n^{\circ}$ 13.445/17 instituiu a Lei da Migração, trazendo regulamentação a direitos e garantias ao imigrante e dando-lhe o reconhecimento como sujeito de direitos, baseando-se na dignidade da pessoa humana. Assegurando inclusive o acesso a Seguridade Social (saúde, 
assistência e previdência), bem como a outros direitos sociais como direito ao acesso à educação, trabalho, lazer e assegurando entre os indivíduos a igualdade de tratamentos e oportunidades.

Geralmente um indivíduo que decide migrar não possui em seus país de origem garantias de uma vivência digna, sofrendo até violações de direitos humanos. Muitos não possuem acesso a direitos sociais básicos como educação, moradia, alimentação e garantias trabalhistas e buscam no país para qual irão migrar essa assistência. O país que receberá esse indivíduo, que já pode ser considerado vulnerável em vários aspectos, deve garantir esses direitos básicos (VERAS, 2010).

A lei descreve ainda o conceito de imigrante em seu art. $1^{\circ}, \S 1^{\circ}, \mathrm{II}$, que diz que imigrante seria "pessoa nacional de outro país ou apátrida que trabalha ou reside e se estabelece temporária ou definitivamente no Brasil”. Mazzuoli (2015) conceitua estrangeiro como os demais indivíduos que estão em um país, seja temporária ou definitivamente, mas possuem outra ou nenhuma nacionalidade. Veras (2010), assevera também que a migração não gera apenas uma alteração de efeitos territoriais, mas também sociais, uma vez que interfere na seara residencial, de trabalho e de amizades.

Neste sentido, é importante destacar que o art. 203, V, da CRFB/88 preceitua que a assistência social que será concedida "a quem dela necessitar", observa-se que o texto constitucional não faz nenhuma referência a qualidades do indivíduo de ordem étnica, cultural ou de nacionalidade. Além disso, no art. 194, I, da CRFB/88 estabelece como um dos princípios da Seguridade Social a universalidade, ou seja, ela deve ser acessível a todos sem distinção, reforçando a ideia de igualdade.

Logo no art. $1^{\circ}$ da lei 8.742/93, expõe-se que a assistência social seria direito do cidadão, o que levou a muitos entenderem como sendo apenas um direito de nacionais. Segundo Bulos (2015), a cidadania seria um status que qualificaria o nacional a exercer seus direitos políticos ativos e passivos, ou seja, de votar e ser votado.

O Decreto $\mathrm{n}^{\mathrm{o}} 7.617$, de 17 de novembro de 2011, em seu art. $7^{\circ}$ dispõe que será prestado o benefício a brasileiros natos ou naturalizados, que preencham os critérios legais e estejam residindo no Brasil, portanto, a celeuma paira diante dos estrangeiros que residem no Brasil, no entanto, não são naturalizados.

Diante desse argumento, o INSS vem indeferindo requerimentos de benefícios de prestação continuada a estrangeiros, mesmo sendo provados os requisitos inerentes ao percebimento, quais 
sejam: a miserabilidade, idade de 65 (sessenta e cinco) anos para os idosos ou prova da deficiência, fundamentando em linhas gerais a ausência de cidadania brasileira.

O Brasil tem sido bastante aberto no recebimento de estrangeiros, permitindo inclusive, que continuem residindo aqui, não teria motivo então para extingui-los da Seguridade Social pelo mero fato de não possuírem a nacionalidade brasileira. A exclusão do estrangeiro estaria afrontando o princípio da igualdade, uma vez que estaria fazendo acepção entre brasileiros e estrangeiros (IBRAHIM, 2015).

$\mathrm{O}$ art. $5^{\circ}$, caput, da CRFB/88 assegura que: "Todos são iguais perante a lei, sem distinção de qualquer natureza, garantindo-se aos brasileiros e aos estrangeiros residentes no País a inviolabilidade do direito à vida, à liberdade, à igualdade, à segurança e à propriedade". Agra (2018) dispõe que em decorrência desse princípio a lei não pode criar diferenças fáticas onde não há e apenas se justificaria desigualdade com o escopo de gerar a igualdade fática. Trata-se da chamada igualdade material aristotélica.

Além disso, a negativa configuraria grave afronta aos fundamentos da República Federativa do Brasil, constante no texto da Carta Magna de 1988, como a dignidade da pessoa humana presente no art. $1^{\mathrm{a}}$, III, que de acordo com Agra (2018) a dignidade da pessoa humana seria um complexo de direitos inerentes ao ser humano e que sem eles nos tornaríamos apenas coisa.

Bulos, ao conceituar princípios constitucionais aduz que o interesse tutelado numa norma é tão importante quanto um tutelado por um princípio, diz ainda que: "Violá-lo é tão grave quanto transgredir uma norma qualquer, pois não há gradação quanto ao nível de desrespeito a um bem jurídico" (BULOS, 2015, p. 508).

Entende-se que a lei não poderia restringir o benefício de prestação continuada para estrangeiros já que o texto constitucional, que está no topo do ordenamento jurídico, não o faz. A mera condição de estrangeiro não deve ser impeditiva do recebimento se preenchidos os demais requisitos para concessão.

Sob a ótica de Ibrahim (2015), a restrição somente seria aceitável caso a União provasse veementemente, não apenas com alegações, mas com provas concretas, a impossibilidade de prestação. O mesmo autor aduz ainda que atualmente não há motivo para a não abrangência dos estrangeiros residentes no país, portanto, não haveria justificação razoável para ocorrência desta discriminação, além do mais por tratar-se de garantia ao mínimo existencial (IBRAHIM, 2015). 
No ano de 2017, em sede recurso extraordinário de repercussão geral o STF entendeu ser possível a concessão do BPC a estrangeiros residentes no país, ou seja, todo o Poder Judiciário deve aplicar esta tese em casos semelhantes. Foi aprovado o tema 173 da repercussão geral: "Os estrangeiros residentes no País são beneficiários da assistência social prevista no artigo 203, inciso V, da Constituição Federal, uma vez atendidos os requisitos constitucionais e legais" (STF. RE 587970, 2017).

O STF decidiu que a condição de estrangeiro não deve ser óbice para o percebimento do BPC, pago pelo INSS, aos que preencherem os requisitos. Negou-se provimento ao RE 587970, em que o INSS recorria da decisão proferida pela Primeira Turma Recursal do Juizado Especial Federal da $3^{\text {a }}$ Região, que julgou procedente o pedido de benefício assistencial a uma italiana residente no Brasil há cinquenta e sete anos.

Em seu voto, o relator ministro Marco Aurélio defendeu que a intenção do constituinte foi conferir proteção àqueles que vivem na pobreza, sem distinção. Destaca ainda que no conflito entre visões jurídicas, deve prevalecer aquela em consonância com a dignidade da pessoa humana. Salienta o fato do Brasil, desde sua origem, ser formado por imigrantes (STF RE 587970, 2017), vejamos:

(...) Em verdade, ao lado dos povos indígenas, o País foi formado por imigrantes, em sua maioria europeus, os quais fomentaram o desenvolvimento da nação e contribuíram sobremaneira para a criação e a consolidação da cultura brasileira. Incorporados foram a língua, a culinária, as tradições, os ritmos musicais, entre outros. Desde a criação da nação brasileira, a presença do estrangeiro no País foi incentivada e tolerada, não sendo coerente com a história estabelecer diferenciação tão somente pela nacionalidade, especialmente quando a dignidade está em cheque em momento de fragilidade do ser humano - idade avançada ou algum tipo de deficiência. (...)

Do voto do ministro Alexandre de Moraes foi possível concluir que o legislador constitucional teria utilizado um critério de territorialidade e não de nacionalidade ao definir quem receberia o benefício. Ou seja, aquele que estiver em território nacional e ali fixou residência com animus definitivo, seja brasileiro nato ou naturalizado, estrangeiro residente no Brasil, terá direito ao BPC (STF RE 587970, 2017).

\subsection{Panorama atual após o julgamento do Recurso Extraordinário 587.970}


Antes mesmo da tese de repercussão geral fixada pelo STF, a jurisprudência nos Tribunais Regionais Federais já julgava favoravelmente a concessão do BPC aos estrangeiros com residência no Brasil, além disso, os doutrinadores já entendiam pelo cabimento deste direito.

Mesmo a legislação não possuindo em seu seio a expressão efeito vinculante para as decisões de repercussão geral do STF, doutrinariamente entende-se que as teses fixadas são de observância obrigatória perante os demais órgãos do Poder Judiciário. O Acórdão terá força de precedente vinculante perante os demais órgãos jurisdicionais. Câmara (2017, p. 480), por sua vez, conclui que:

Por fim, deve-se dizer que no caso de o precedente vinculante fixado através da técnica do julgamento de recursos excepcionais repetitivos versar sobre questão relativa a prestação de serviço público objeto de concessão, permissão ou autorização (como se dá, por exemplo, com serviços como telefonia ou fornecimento de energia elétrica), o resultado do julgamento será comunicado ao órgão, ente ou agência reguladora competente para fiscalizar a efetiva aplicação, por parte dos entes sujeitos a regulação, da tese adotada (art. 1.040, IV).

Ou seja, o autor afirma que a tese de repercussão geral deverá ser observada tanto pelo Poder Judiciário quanto pelas demais entidades competentes de administrar o serviço de que trata a decisão do STF, essa observância é obrigatória e possui natureza vinculante.

Ocorre que, mesmo diante da força vinculante da tese elaborada pelo Supremo, a autarquia previdenciária continua negando os pedidos de amparo assistencial com fundamento na exigência de ser o estrangeiro naturalizado.

A Defensoria Pública da União (DPU), que é um órgão que atua na assistência jurídica de indivíduos hipossuficientes e tem competência para atuar perante o Poder Judiciário da União, é procurada diariamente por diversas pessoas em busca de orientação jurídica, tendo inclusive, atuado como amicus curiae no RE 587970. Em diversas situações, a população procura a DPU por ver seus direitos violados pelo INSS e necessitarem de um advogado público para pleitear judicialmente a garantia da aplicação da lei, em casos de indeferimentos arbitrários e ilegais de benefícios perante o INSS.

Em 2018, um italiano de oitenta e um anos, residente no Brasil, no estado da Bahia, desde 1997, procurou o órgão defensório federal, pois teve seu pedido administrativo indeferido pelo INSS sob argumento de que inexistiria previsão legal de concessão do amparo a estrangeiros e a 
exigência de naturalização, mesmo tendo preenchido os requisitos de idade e miserabilidade, já que não tinha meios de prover o próprio sustento ou de tê-lo provido por sua família ${ }^{32}$.

Diante disso, foi ajuizada uma ação perante a Justiça Federal, a qual foi julgada procedente pela $9^{\circ}$ Vara do Juizado Especial Federal da Seção Judiciária do Estado da Bahia, que condenou o INSS a conceder o benefício assistencial para o autor no prazo de quinze dias, bem como ao pagamento dos valores atrasados desde a data de realização da perícia social.

A DPU ajuizou ainda ação civil pública (ACP) de n $n^{o}$ 1026018-31.2018.4.01.3400 no Distrito Federal pois a nacionalidade continua sendo motivo para indeferimento dos pedidos de amparo junto ao INSS. O objeto da ação foi uma Portaria Conjunta $n^{\circ} 03$ que o Ministro de Estado do Desenvolvimento Social e o Presidente do INSS editaram e que em seu art. $7^{\circ}$, caput, I, previa que para requerer o benefício seria necessário ter nacionalidade brasileira, sendo nato, naturalizado ou português equiparado. Em suma, foi requerida a anulação/cassação do referido artigo, bem como, que o INSS se abstivesse de indeferir pedidos com base unicamente no critério de nacionalidade. Em decisão que deferiu a tutela de urgência, o juiz argumentou que a administração havia ido além dos poderes regulamentares a ela investidos e determinou a suspensão da eficácia do artigo objeto da ação.

No entanto, sentença extinguiu o processo sem resolução do mérito devido à litispendência da ACP 0006972-83.2012.4.01.3400 (21 ${ }^{\mathrm{a}}$ Vara Federal/SJDF) e a ACP 501926018.2018.4.04.7107 ( $3^{\mathrm{a}}$ Vara Federal de Caxias do Sul/RS). Quanto à ACP 000697283.2012.4.01.3400, a sentença entendeu pela a declaração de inconstitucionalidade incidenter tantum da parte do art. $1^{\circ}$, da Lei $\mathrm{n}^{\circ}$ 8.742/1993, que restringe aos cidadãos brasileiros o direito à assistência social, pelo que determinou à Autarquia abster-se de indeferir os requerimentos de benefícios assistenciais que tenham por fundamento, de modo exclusivo, a nacionalidade dos requerentes. Foi negado provimento ao apelo do INSS e da União.

O que se verifica é que na prática, dificilmente um estrangeiro que não seja naturalizado ou português equiparado irá conseguir administrativamente a concessão do benefício assistencial, contudo, com a negativa e a judicialização da demanda, caso sejam preenchidos os requisitos, o indivíduo estrangeiro irá obter êxito na concessão do amparo.

\footnotetext{
32 https://www.dpu.def.br/noticias-bahia/136-noticias-ba-slideshow/48565-dpu-garante-beneficio-assistencial-aitaliano-residente-no-brasil
} 
Um dos princípios da Seguridade Social é a universalidade, que se consubstancia do princípio da igualdade, tendo com premissa tratar igualmente aqueles que estão perante um risco social (TELES, 2016). Segundo Sposati (2013), essa universalidade mostra-se em confronto com as regras do capital, que em regra são pautadas na desigualdade.

De mais a mais, o não reconhecimento desse direito a estrangeiros é um caminho ao retrocesso social e afronta a nova ordem contemporânea que é baseada na aplicação dos direitos humanos e dos princípios democráticos.

\section{RESULTADOS E DISCUSSÕES}

Diante da pesquisa bibliográfica e jurisprudencial realizada foram obtidos alguns resultados que amadurecem o campo de debate sobre o tema, bem como se levanta a discussão de alguns pontos. Com isso, compreende-se pela constitucionalidade da concessão de BPC para estrangeiros residentes no Brasil, já que sua vedação traz direta afronta a princípios e a norma constitucional.

\subsection{Assistência Social no Brasil}

A assistência social torna-se extremamente necessária no contexto histórico brasileiro, que traz as desigualdades desde o seu descobrimento e a assistência veio como uma política de desenvolvimento que visa garantir um mínimo existencial para aqueles que se encontram em situação de disparidade com as demais pessoas da sociedade. De acordo com Agra (2018), a assistência surgiu como um meio de evitar a profunda miséria da nação e garantir a segurança social e o crescimento econômico.

Uma característica das normas sociais, que traz os direitos sociais que são de segunda geração, é que elas representam o compromisso do Estado com a justiça social, redução das desigualdades e proteção aos hipossuficientes.

Com a informatização do trabalho manual, muitos trabalhadores se viram obrigados a trabalhar por conta própria, o que faz diminuir a taxa de contribuição previdenciária. Políticas de incentivo a contribuição previdenciária por parte dos estrangeiros, em sua maioria trabalhadores informais, fariam aumentar a proteção social em eventos incapacitantes para o trabalho. 
$\mathrm{O}$ art. 203, V, da CRFB/88, neste sentido, traz a possibilidade de concessão do BPC aqueles que preencherem os requisitos legais (miserabilidade e deficiência/idade). Como não traz a necessidade de preenchimento de nenhum critério relacionado à cidadania brasileira, entende-se que o texto constitucional não tinha o objetivo de vedar o percebimento com base em critérios de nacionalidade.

Deverá o beneficiário demonstrar possuir mais de 65 (sessenta e cinco) anos no caso de BPC a idosos; prova da deficiência que impossibilite o indivíduo de viver em pé de igualdade com as demais pessoas e que inviabilize a realização de tarefas do dia a dia, essa deficiência deverá ter o período mínimo de dois anos e em casos de reversão da patologia, é perfeitamente possível a cessação do benefício; por fim, deverá ser provado o critério da miserabilidade de que o indivíduo não possuía meios de garantir a sua subsistência nem de tê-la havida por sua família. Esses são os requisitos trazidos pela LOAS e que também não criam óbice para o percebimento do benefício por estrangeiros.

Como foi demonstrado, o critério da miserabilidade passou por mudanças jurisprudenciais e apesar do INSS não estar vinculado a seguir o entendimento judicial, no ajuizamento da demanda haverá viabilidade de vitória já que o juiz analisará a pobreza em um contexto macrossocial e não a cidadania do pleiteante.

A CFRB/88 juntamente com a LOAS vem buscando a proteção daqueles que mais necessitam, objetivando prover o mínimo existencial, como meio de garantir uma certa equidade entre os membros da sociedade e com isso abarcam todos aqueles que necessitam.

\subsection{Concessão de Benefício de Prestação Continuada aos Estrangeiros Residentes no Brasil}

A lei da migração (Lei no 13.445/17) traz proteção e direitos ao imigrante, conceituando o que seria imigrante e assegurando o direito a Seguridade Social e outros direitos sociais.

O texto constitucional, todavia, goza de hierarquia perante as demais normas do corpo jurídico nacional, diante de tal afirmativa, não há nenhuma restrição trazida por ele a aplicação da assistência social a estrangeiros. Como bem frisado durante todo o trabalho, trata-se de direito garantido a todos, sem distinções de raça, religião, etnia e de origem.

Por isso, percebe-se que um dos princípios da hermenêutica constitucional contemporânea é o da Supremacia da Constituição, ou seja, a Constituição goza de supremacia diante das demais 
normas, não se admitindo nenhuma interpretação contrária a ela. Exige-se a necessidade de conciliar os dispositivos que estão em rota de colisão no caso concreto.

A restrição a concessão de BPC pelo estrangeiro, conforme especificado, afrontaria os princípios constitucionais da igualdade e da dignidade da pessoa humana. Agra (2018, p. 210) assevera que o princípio da isonomia busca uma igualdade jurídica, de direitos entre os cidadãos, vejamos:

Através deste princípio não se tenciona igualar os homens de forma arbitrária, pois, nos casos em que foi tentado, essa política resvalou em redundante fracasso, como nas políticas implementadas no início da Revolução Chinesa. A igualdade almejada é a jurídica, em que a lei não pode discriminar cidadãos que estejam em semelhantes situações.

Diante do arcabouço técnico, frisa-se que em sede de RE, o INSS recorreu de decisão que concedeu o BPC a uma italiana residente no Brasil há 57 (cinquenta e sete anos), o STF estabeleceu repercussão geral e fixou tese de que: "Os estrangeiros residentes no País são beneficiários da assistência social prevista no artigo 203, inciso V, da Constituição Federal, uma vez atendidos os requisitos constitucionais e legais" (STF RE 587970, 2017).

No voto do ministro relator Marco Aurélio foi possível depreender que o Brasil nunca criou restrições para a chegada e moradia de estrangeiros, fazendo isso inclusive, parte de seu contexto de desenvolvimento histórico, não haveria motivos então para a lei infralegal (já que a CRFB/88 não o faz) trazer impedimentos dessa natureza. O voto do ministro Alexandre de Moraes levantou o argumento de que o texto constitucional usa de um critério territorial e não de nacionalidade (STF RE 587970, 2017).

Para conferir um mínimo de segurança jurídica ao INSS ou ao Poder Judiciário na concessão do BPC a estrangeiros, é necessário que o Congresso Nacional atue rapidamente na votação de uma alteração no art. $7^{\circ}$, do decreto $n^{\circ} 7.617 / 11$ para não restringir o benefício a brasileiros natos ou naturalizados, pois assim, a norma infralegal caminharia em conformidade com o texto constitucional.

\subsection{Panorama atual após o julgamento do Recurso Extraordinário 587.970}

Mesmo diante da tese de repercussão geral fixada pelo INSS, os TRFs já entendiam pela possibilidade de concessão de BPC a estrangeiros residentes no Brasil. 
Sabe-se que o RE possui efeito vinculante perante os demais órgãos jurisdicionais, bem como, perante a entidade da administração pública que presta o serviço tratado, conforme o entendimento de Câmara (2017).

Contudo, mesmo diante da força vinculante que se entende ter esse tipo de decisão, o INSS se nega a aceitar administrativamente o benefício. Como se sabe, a decisão do STF não vincula o Poder Legislativo e se valendo disso que a autarquia, através do Ministro do Desenvolvimento Social e o Presidente do INSS editou a Portaria Conjunta $n^{\circ} 03$ em que o art. $7^{\circ}$, caput, I, que previa a necessidade da naturalização para que os estrangeiros fossem beneficiados com o amparo.

No entanto, a DPU ajuizou a ação civil pública requerendo a cassação/anulação do citado artigo, bem como, que o INSS deveria se abster de negar benefícios assistenciais com base apenas no critério de nacionalidade. O juiz deferiu a tutela de urgência pedida na ação pela DPU.

Atenta-se pela afronta ainda do princípio da seguridade social da universalidade, o qual garante que todos, preenchendo os requisitos, têm direito ao aproveitamento dos benefícios da seguridade social.

Reforça-se, assim, a necessidade de atuação do Poder Legislativo a fim de editar o art. $7^{\circ}$, do decreto $\mathrm{n}^{\circ}$ 7.617/11 para que não seja necessário cada vez que um estrangeiro requerer o BPC tenha que ajuizar uma demanda judicial para conseguir seu benefício. Por tratar-se de um benefício assistencial que possui caráter alimentar e pela sabida demora no julgamento das ações no Poder Judiciário, deve ter seu devido regulamento infralegal (pois o constitucional já possui).

\section{CONSIDERAÇÕES FINAIS}

O presente trabalho abordou os preceitos da assistência social no Brasil, sua aplicação e seus requisitos; a possibilidade de concessão de BPC a estrangeiros residentes no Brasil; e o panorama atual após o julgamento do RE que 587.970 que reconheceu a possibilidade de aplicação do benefício aos estrangeiros.

A assistência social, regulada pelo art. 203 e 204 da CRFB/88 e pela LOAS (Lei n8.742/93), traz o BPC como um amparo assistencial aqueles que em eventos de velhice e deficiência, demonstrada a miserabilidade, terão direito a receber do Estado o auxílio no valor de um salário mínimo, abrangendo a norma constitucional todos aqueles que necessitam. É um Direito 
Fundamental Social, devido a todos, sem distinção pautada na nacionalidade, com o fim de concretizar a garantia ao mínimo existencial e alcance da dignidade da pessoa humana.

Demonstrou-se com a presente pesquisa que o argumento do INSS ataca a Constituição da República e seus princípios, entendendo-se pela constitucionalidade desse direito a estrangeiros residentes no Brasil.

Sendo assim, através dos conceitos expostos no presente trabalho, infere-se que entendimento contrário causa enorme desequilíbrio social, já que o Brasil sempre foi receptivo a chegada de estrangeiros no território e a exclusão deles da assistência social feriria a CFRB/88. Não há indícios dos prejuízos causados pelo reconhecimento desse direito, prejuízos esses que devem ser demonstrados concretamente para embasar argumento contrário ao BPC para estrangeiros.

Também é importante destacar a importância da regulamentação desse direito na norma infralegal, para que o INSS possa deferir os pedidos realizados na via administrativa e os beneficiários não necessitem passar pelas intempéries de um moroso processo judicial, prejudicando ainda mais a sua dignidade como pessoa humana.

Portanto, o trabalho de modo geral visou demonstrar a constitucionalidade quanto a assegurar aos estrangeiros residentes no Brasil o amparo social e como consequência o direito de viver dignamente em momentos de vulnerabilidade social, com a aplicação dos Princípios da Dignidade da Pessoa Humana e Isonomia, através da concessão do BPC.

\section{REFERÊNCIAS}

AGRA, Walber de Moura. Curso de Direito Constitucional. 9. ed. São Paulo: Fórum, 2018.

BRASIL. Constituição (1988). Constituição da República Federativa do Brasil. Brasília: Senado Federal, 1988.

BRASIL. Decreto no 7.617, de 17 de novembro de 2011. Disponível em: http://www.planalto.gov.br/ccivil_03/_Ato2011-2014/2011/Decreto/D7617.htm. Acesso em: 06 out. 2019.

BRASIL. Lei n. 13.445 , de 24 de maio de 2017. Disponível em: http://www.planalto.gov.br/ccivil_03/_ato2015-2018/2017/lei/113445.htm\#art125. Acesso em: 28 set. 2019. 
BRASIL. Supremo Tribunal Federal (Tribunal Pleno). Acórdão. Agravo regimental no recurso extraordinário com agravo no 834476/RJ. Agravante: Maria Pelônia Santos. Agravado: Instituto Nacional do Seguro Social - INSS. Relator: Ministro Dias Toffoli, 03 de março de 2015. Disponível em:

http://redir.stf.jus.br/paginadorpub/paginador.jsp?docTP=TP\&docID=8163859. Acesso em: 7 set. 2019.

BRASIL. Supremo Tribunal Federal (Tribunal Pleno). Acórdão. Recurso Extraordinário no 567.985/MT. Reclamante: Instituto Nacional do Seguro Social - INSS. Reclamada: Alzira Maria de Oliveira Souza. Relator: Ministro Marco Aurélio, 18 de abril de 2013. Disponível em: http://redir.stf.jus.br/paginadorpub/paginador.jsp?docTP=TP\&docID=4614447. Acesso em: 7 set. 2019.

BRASIL. Supremo Tribunal Federal (Tribunal Pleno). Acórdão. Recurso Extraordinário no 580.963/PR. Reclamante: Instituto Nacional do Seguro Social - INSS. Reclamada: Blandina Pereira Dias. Relator: Ministro Gilmar Mendes, 18 de abril de 2013. Disponível em: http://webcache.googleusercontent.com/search?q=cache:Ucrzd2YS280J:www.stf.jus.br/portal/pr ocesso/verProcessoPeca.asp\%3Fid\%3D184261323\%26tipoApp\%3D.pdf+\&cd=1\&hl=ptBR\&ct=clnk\&gl=br. Acesso em: 7 set. 2019.

BRASIL. Supremo Tribunal Federal (Tribunal Pleno). Acórdão. Recurso Extraordinário no 587.970/SP. Reclamante: Instituto Nacional do Seguro Social - INSS. Reclamada: Felícia Mazzitello Albanese. Relator: Ministro Marco Aurélio, 20 de abril de 2017. Disponível em: http://redir.stf.jus.br/estfvisualizadorpub/jsp/consultarprocessoeletronico/ConsultarProcessoEletro nico.jsf?seqobjetoincidente=2621386. Acesso em: 17 set. 2019.

BRASIL. Turma Nacional de Uniformização. Súmula no 79. Nas ações em que se postula benefício assistencial, é necessária a comprovação das condições socioeconômicas do autor por laudo de assistente social, por auto de constatação lavrado por oficial de justiça ou, sendo inviabilizados os referidos meios, por prova testemunhal. Brasília, DF: Turma Nacional de Uniformização. Disponível em:

https://www.cjf.jus.br/phpdoc/virtus/sumula.php?nsul=79\&PHPSESSID=2nigr9od1e41p3k5pa8d 086g82. Acesso em: 20 out. 2019.

BULOS, Uadi Lammêgo. Curso de Direto Constitucional. 9. ed. São Paulo: Saraiva, 2015.

CÂMARA, Alexandre Freitas. O Novo Processo Civil Brasileiro. 3. ed. São Paulo: Atlas, 2017. CANOTILHO, José Joaquim Gomes. Direito Constitucional. 6. ed. Coimbra: Almedina, 1993. GIL, Antônio Carlos. Métodos e Técnicas de Pesquisa Social. 6. ed. São Paulo: Atlas S. A., 2008.

IBRAHIM, Fábio Zambitte. Curso de Direito Previdenciário. 20. ed. Rio de Janeiro: Impetus, 2015. 
MARCONI, Marina de Andrade; LAKATOS, Eva Maria. Fundamentos de Metodologia Científica. 5. ed. São Paulo: Atlas S. A., 2003.

MAZZUOLI, Valério de Oliveira. Curso de Direito Internacional Público. 9. ed. rev. atual. e ampl. São Paulo: Revista dos Tribunais, 2015.

MGM. DPU obtém tutela de urgência em ação contra o INSS para beneficiar migrantes. Disponível em: https://www.dpu.def.br/noticias-institucional/233-slideshow/48042-dpu-obtemtutela-de-urgencia-em-acao-contra-o-inss-para-beneficiar-migrantes. Acesso em: 6 out. 2019.

MML/MMO. DPU garante benefício assistencial a italiano residente no Brasil. Disponível em: https://www.dpu.def.br/noticias-bahia/136-noticias-ba-slideshow/48565-dpu-garantebeneficio-assistencial-a-italiano-residente-no-brasil. Acesso em: 6 out. 2019.

MOTA, Ana Elizabete. Seguridade Social Brasileira: Desenvolvimento Histórico e Tendências Recentes. Serviço Social e Saúde: formação e trabalho profissional. São Paulo: Cortez, 3. ed, p. 40-49, 2006. Disponível em: http://www.fnepas.org.br/pdf/servico_social_saude/texto1-2.pdf. Acesso em: 25 jun. 2020.

SPOSATI, Adaílza. A menina LOAS: um processo de construção da assistência social. 3. ed. São Paulo: Cortez, 2007.

SPOSATI, Adaílza. Proteção social e seguridade social no Brasil: pautas para o trabalho do assistente social. Serv. Soc. Soc. São Paulo, n.116, p.652-674, 2013. Disponível em: https://www.scielo.br/pdf/sssoc/n116/05.pdf. Acesso em: 25 jun. 2020.

TELES, Katia Cristine Oliveira. A Aplicação do Princípio da Subsidiariedade como Forma de Alcançar a Universalidade na Seguridade Social por Meio do Subsistema de Assistência Social. Tese (Doutorado em Direito) - Universidade Presbiteriana Mackenzie. São Paulo, 2016.

VERAS, Nathália Santos. Direitos Humanos dos Migrantes na Jurisprudência Consultiva da Corte Interamericana de Direitos Humanos. Textos\&Debates. Boa Vista, n.18, p. 251-268, 2010. Disponível em: http://ufrr.br/ppgsof/index.php/component/phocadownload/category/4-anaiscomunicacao.html?download=140:041. Acesso em: 22 jun. 2020.

\title{
CONSTITUTIONALITY OF THE CONCESSION OF BENEFIT OF CONTINUED PROVISION TO FOREIGN RESIDENTS IN BRAZIL IN SITUATION OF MISERABILITY
}

\begin{abstract}
This article deals with the right to the Continued Payment Benefit to foreigners resident in Brazil and who meet the requirements of disability, age and have no means of maintaining their own support, as well as having
\end{abstract}


it maintained by their family. Therefore, this research will be built through legal and social concepts, brought by legal scholars, among them Walber de Moura Agra (2018), Fábio Zambitte Ibrahim (2015) and Alexandre Freitas Câmara (2017), in order to ensure the application of some constitutional principles such as human dignity and equality. In addition, an analysis will be made of the benefit and its criteria for granting, its legal support and case law. The specific objectives are to describe about social assistance in Brazil; investigate the possibility of granting BPC to foreigners residing in the country; and, to present some cases after the Extraordinary Appeal 587.970 of the Supreme Federal Court. The methodology used was the dialectical method, through the qualitative approach, with bibliographic-descriptive character. With the lack of research, it is concluded that the constitutionality of granting social protection to foreigners residing in the country.

Keywords: Social assistance. Continued Payment Benefit. Foreigners. General repercussion. Possibility. 